\title{
Advanced Characterization and Modification of Nanoporous Metals
}

\author{
Roger C. Newman and AmirHossein Foroozan Ebrahimy \\ University of Toronto, Department of Chemical Engineering and Applied Chemistry \\ 200 College Street, Toronto, M5S 3E5, Ontario, Canada \\ roger.newman@utoronto.ca; a.foroozanebrahimy@mail.utoronto.ca
}

\section{Extended Abstract}

The results of a number of recent investigations into nanoporous metals will be summarized, and some general principles elucidated. The most common nanoporous metal, "nanoporous gold" (NPG) is actually several variants, made from Ag-Au precursors with low (5 at.\%), or high (up to 30 at.\%) Au, with or without small additions of elements such as Pt.

NPG is usually synthesized by dealloying - the selective electrolytic dissolution of more reactive element(s), in this case $\mathrm{Ag}$, from a solid solution. The operative mass transport process is diffusion of $\mathrm{Au}$ (and $\mathrm{Pt}$, where present) at the solidelectrolyte interface, allowing the continual emergence of Ag.

One would like to use NPG for various applications, such as membranes, catalysts, sensors, and so on. One drawback of ordinary NPG for such purposes is the continued mobility of $\mathrm{Au}$ at the surface, which leads to coarsening of the structure, especially at elevated temperatures. The addition of small amounts of Pt [1] hinders such coarsening, even at low Au contents [2] and also has obvious relevance to catalysis.

Atom Probe Tomography (APT) has proved very successful for the nanoscale analysis of NPG [2-4]. The essential step was to learn how to electroplate $\mathrm{Cu}$ into the pores, achieving complete filling, at least locally. This strengthened the material against the otherwise inevitable fractures that would occur during the APT analysis.

Heating of NPG, in air or inert environments, causes surface segregation that can be beneficial, especially for catalysis $[4,5]$. Much remains to be learned about the operative mass transport processes.

Adsorption on to the ligament surfaces in NPG can alter the electrical resistance of the metal itself, leading to potential applications in gas sensing [6].

\section{References}

[1] A.A. Vega and R.C. Newman, "Nanoporous metals fabricated through electrochemical dealloying of Ag-Au-Pt with systematic variation of Au: Pt ratio," J. Electrochem. Soc., vol. 161, no. 1, pp. C1-C10, 2013.

[2] A.F. Ebrahimy, B. Langelier and R.C. Newman, "Atom probe tomography of nanoporous gold formed by dealloying lean noble alloys," Materials Today Communications, vol. 25, pp. 101371-101381, 2020.

[3] A.A. El-Zoka, B. Langelier, A. Korinek, G.A. Botton and R.C. Newman, "Nanoscale mechanism of the stabilization of nanoporous gold by alloyed platinum," Nanoscale, vol. 10, no. 10, pp. 4904-4912, 2018.

[4] A.A. El-Zoka, B. Langelier, G.A. Botton and R.C. Newman, "Morphological evolution of Pt-modified nanoporous gold after thermal coarsening in reductive and oxidative environments," npj Materials Degradation, vol. 4, no. 1, pp. 1-6, 2020.

[5] A.A. Vega and R.C. Newman, "Beneficial effects of adsorbate-induced surface segregation of Pt in nanoporous metals fabricated by dealloying of Ag-Au-Pt alloys," J. Electrochem. Soc., vol. 161, no. 1, pp. C11-C19, 2014.

[6] T.S.B. Wong and R.C. Newman, "Nanoporous gold as a VOC sensor, based on nanoscale electrical phenomena and convolutional Neural Networks," Sensors, vol. 20, no. 10, pp. 2851-2866, 2020. 